\title{
Ageing effects in a Cu-Al-Ni shape memory alloy
}

\author{
T. Daricek, J. Lasek, N. Zarubova, V. Novak and P. Bartuska \\ Institute of Physics, Academy of Sciences of the Czech Republic, Na Slovance 2, \\ 18221 Prague 8, Czech Republic
}

\begin{abstract}
Ageing of a Cu-14.3Al-4.1Ni (wt.\%) shape memory alloy was investigated by resistometry and scanning electron microscopy. Four stages were distinguished in isochronal annealing experiments. Underlying processes were discussed with respect to the changes observed in the particular stages. In the early stages of ageing, annealing of quenched-in vacancies is probably the dominant process; the effect of ordering processes seems to be negligible. A decrease in the hysteresis width precedes a pronounced $\gamma_{2}$ phase precipitation, which takes place at temperatures above $300^{\circ} \mathrm{C}$. Above $370^{\circ} \mathrm{C}$, the alloy ability of martensitic transformation is being lost.
\end{abstract}

\section{INTRODUCTION}

Ageing of Cu-Al-Ni alloys showing the thermoelastic martensitic transformation has been studied by many authors [1-13]. A shift of the transformation temperatures and changes in the transformation hysteresis due to annealing have been well documented. In the early stages of ageing, changes in the degree and type of order of the parent $\beta_{1}$ phase are thought to be a significant process $[3,8,10]$. Precipitation of stable phases $\left(\gamma_{2}, \alpha\right)$ has been documented to occur in the later stages, leading to the decomposition of the metastable parent phase and in turn to the lost of the shape memory [2-6].

Isothermal ageing of a Cu-12.9Al-4Ni (wt.\%) alloy was carried out by Rodríguez and Guénin [10]. Three stages of ageing could be distinguished at annealing temperatures below $360^{\circ} \mathrm{C}$. In the first stage, the transformation temperatures $\left(\mathrm{M}_{\mathrm{s}}, \mathrm{M}_{\mathrm{f}}, \mathrm{A}_{\mathrm{s}}, \mathrm{A}_{\mathrm{f}}\right)$ remain stable or slightly decrease. During the second stage, the transformation temperatures continuously increase without noticeable change in the transformation hysteresis or enthalpy. In the third stage, the martensitic transformation deteriorates, which leads to an increase in the hysteresis and a large decrease in the enthalpy, until no transformation at all is observed.

Similarly to the results of paper [10], three distinct stages of ageing were found also in our recent study [5] where the martensitic transformation was investigated in isochronally annealed samples of a $\mathrm{Cu}-14.3 \mathrm{Al}-4.1 \mathrm{Ni}$ (wt.\%) alloy. Using transmission electron microscopy [TEM], the first $\gamma_{2}$ precipitates were detected at the very beginning of the second stage, and their growth during further ageing was followed. In spite of the detailed structural analysis performed, the changes of the transformation temperatures, particularly of $A_{s}$ and $A_{f}$, were not satisfactorily explained [5]. In the present work, we have attempted to contribute to elucidation of this question utilising resistometry. This method has seldom been used in the research of $\mathrm{Cu}-\mathrm{Al}-\mathrm{Ni}$ alloy ageing up to now $[1,8]$. However, it can detect even subtle structural changes and, if supported by some other method to allow an unambiguous interpretation of the results, it can give valuable information.

\section{EXPERIMENTAL}

A single crystal (60 mm long, $18 \mathrm{~mm}$ in diameter) of a $\mathrm{Cu}-14.3 \mathrm{Al}-4.1 \mathrm{Ni}(\mathrm{wt} . \%)$ alloy was grown by the Bridgman technique. The as-grown single crystal was annealed at $1000^{\circ} \mathrm{C}$ for $1 \mathrm{~h}$ in an argon 
atmosphere and then quenched into a mixture of ice and water. Specimens were prepared from the single crystal by spark cutting, mechanical grinding and chemical polishing in dilute nitric acid.

The specimens for resistometry had dimensions $40 \times 0.8 \times 0.8 \mathrm{~mm}^{3}$. A specimen with welded-to conductors and an attached $\mathrm{NiCr}-\mathrm{Ni}$ thermocouple was placed into a quartz tube (outer diameter $5.5 \mathrm{~mm}$ ). This set was plugged into an aluminium block heated by an insulated resistance wire. To decrease the temperature, the block was inserted into a Dewar flask with liquid nitrogen. The resistance of the specimen was measured using the potentiometric method. The measuring current ( $300 \mathrm{~mA})$ was supplied by a special high-stability source with reversation eliminating parasitic thermovoltages. In the resistivity calculation, corrections for dimension changes with temperature were not applied.

Isochronal annealing were started at $150^{\circ} \mathrm{C}$ and proceeded in $20^{\circ} \mathrm{C}$ steps until $390^{\circ} \mathrm{C}$, the dwell time being $25 \mathrm{~min}$ for each annealing temperature $\left(\mathrm{T}_{\mathrm{an}}\right)$. A temperature cycle comprising full transformation of austenite into martensite and vice versa was carried out two or three times after each annealing. Heating and cooling rates were $\pm 20^{\circ} \mathrm{C} / \mathrm{min}$ excepting the temperature region of the austenite $\leftrightarrow$ martensite $(A \leftrightarrow M)$ transformation where the rates were $\pm 5^{\circ} \mathrm{C} / \mathrm{min}$.

An isothermal annealing was performed by inserting the quartz tube with an as-quenched specimen into the $\mathrm{Al}$ block preheated to $272{ }^{\circ} \mathrm{C}$. The annealing was stopped after $140 \mathrm{~min}$ and then a temperature cycle comprising the martensitic transformation was carried out. The resistivity was measured throughout the experiment.

Microstructure observations and local elemental analyses were done on specimens $14 \times 4 \times 4 \mathrm{~mm}^{3}$ using a Jeol Superprobe 733 scanning electron microscope equipped with an X-ray wave dispersion analyser.

\section{RESULTS}

\subsection{Isochronal annealing}

Examples of the hysteresis loops of the martensitic transformation are given in Fig. 1. The $A \rightarrow M$ transformation always brought about an increase in the resistivity. After annealing at temperatures below $290^{\circ} \mathrm{C}$ the resistivity increase is almost stopped in some sections, which corresponds to an intermittent transformation. At higher $T_{a n}$ the transformation curves are smooth indicating that the transformation is

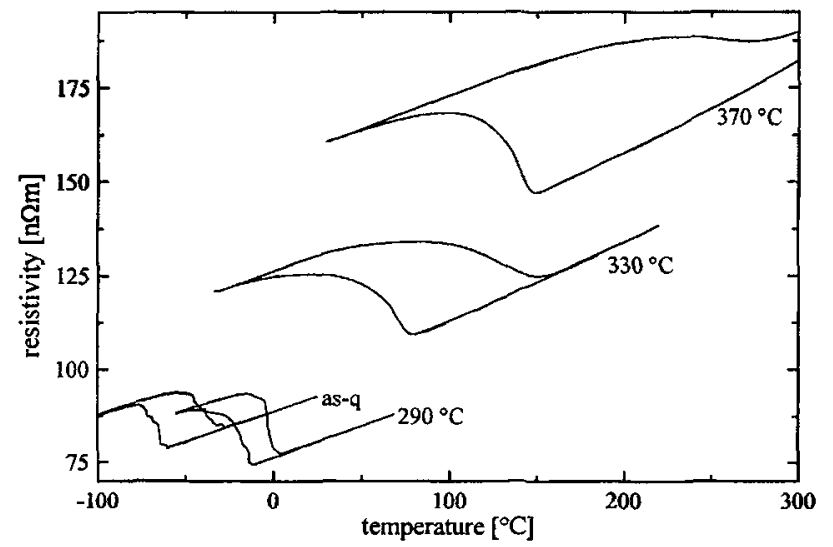

Figure 1. Change of the hysteresis loop of the martensitic transformation during isochronal annealing; the hysteresis loops shown were measured after annealing at temperatures inscribed (as-q....as-quenched specimen). continuous.

The transformation temperatures $M_{s}$ and $A_{f}$, the (structural) resistivity change due to the formation of martensite $(\Delta R)$ and the resistivity of austenite at the reference temperature of $125^{\circ} \mathrm{C}$ $\left(R_{A}\right)$ were measured for each step of the isochronal annealing. If $\mathrm{M}_{\mathrm{s}}$ was greater than $125^{\circ} \mathrm{C}, \mathrm{R}_{\mathrm{A}}$ was determined by extrapolation. The $A_{f}$ temperature could not be determined for $T_{a n}=370$ and $390^{\circ} \mathrm{C}$ as the resistivity began to increase due to ageing effects before the $\mathrm{M} \rightarrow \mathrm{A}$ transformation had been finished. 


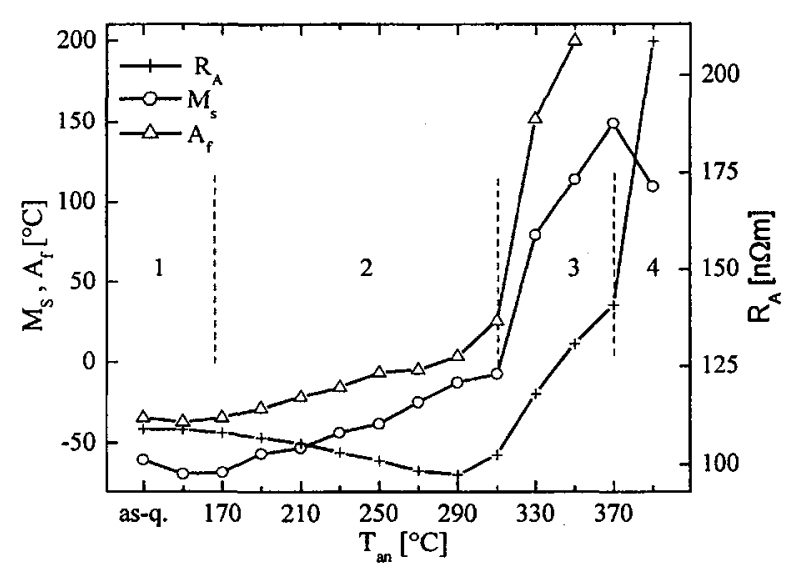

Figure 2. Change of the transformation temperatures $M_{s}$ and $A_{f}$ and of the resistivity of austenite at $125{ }^{\circ} \mathrm{C}, \mathrm{R}_{\mathrm{A}}$, with the isochronal annealing temperature, $T_{\mathrm{an}}$.
The dependencies of $M_{s}, A_{f}$ and $R_{A}$ on $T_{a n}$ are shown in Fig. 2 where average values of 2-3 hysteresis loops are plotted for each $T_{a n}$. Four stages can be distinguished in this isochronal annealing. The $M_{s}$ and $A_{f}$ temperatures slightly fall in stage 1 , slowly increase in stage 2 , and steeply increase in stage 3 . In stage $4, M_{s}$ decreases. The hysteresis width $\left(\mathrm{A}_{\mathrm{f}}-\mathrm{M}_{\mathrm{s}}\right)$ falls at the end of stage 2 while it increases in stage 3 . The resistivity of the austenite, $\mathrm{R}_{\mathrm{A}}$, moderately decreases in stages 1 and 2 , increases in stage 3 and sharply increases in stage 4 . The changes of $\Delta R$ in the first three stages are inexpressive while a sharp drop of $\Delta \mathrm{R}$ is observed in stage 4 .

\subsection{Isothermal annealing at $272{ }^{\circ} \mathrm{C}$}

The time dependence of the resistivity during an isothermal annealing at $272^{\circ} \mathrm{C}$ is shown in Fig. 3 . It was evaluated on the usual assumption that the structural resistivity change, $\Delta R_{t}$, at the dwell time $t$ is proportional to the transformed volume fraction $y$. Hence, $y=\Delta R_{t} / \Delta R_{\infty}$ where $\Delta R_{\infty}$ is the extrapolated

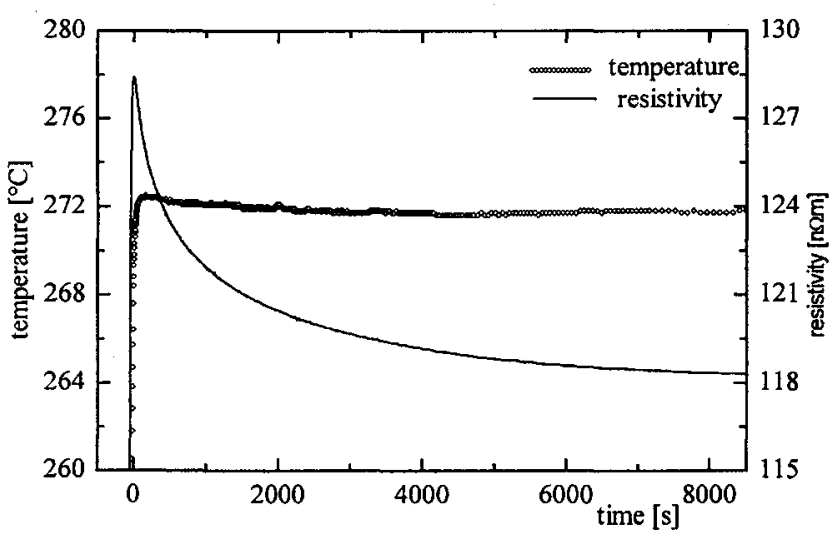

Figure 3. Change of the resistivity during isothermal annealing at $272^{\circ} \mathrm{C}$. structural resistivity change for the equilibrium state after annealing. The time dependence of $y$ was approximated by the Johnson-Mehl-Avrami equation $y=1-\exp \left[-(m t)^{n}\right]$ where the parameter $m$ is a measure of the transformation rate and $n$ relates to the controlling mechanism of the transformation [14]. If the process has the same character during the whole transformation, it can be represented by a straight line in logarithmic coordinates $\ln \ln [1 /(1-y)] \quad v s \ln t$. In this experiment, the line was not straight indicating that at least two processes were passing.

The hysteresis loop measured after this annealing resembled that measured after the isochronal annealing at $290^{\circ} \mathrm{C}$ (Fig. 1).

\subsection{Microstructure and local elemental analysis}

Useful information about the composition shifts during $\gamma_{2}$ phase precipitation could not be obtained until the precipitation was well advanced. A specimen annealed at $350{ }^{\circ} \mathrm{C}$ for $5 \mathrm{~h}$ had a coarsened microstructure with precipitates about $1 \mu \mathrm{m}$ in size. The matrix contained a higher amount of $\mathrm{Cu}$ (by $\approx 3.2 \mathrm{at} . \%$ ), a lower amount of $\mathrm{Al}(\mathrm{by} \approx 3.0$ at.\%) and a slightly lower amount of nickel (by $\approx 0.2$ at.\%) compared with the composition of the precipitates. The compositions of the matrix and of the precipitates are represented 
in the ternary Cu-Al-Ni phase diagram (Fig. 4); they lie approximately on the straight line connecting the $\gamma_{2}$ phase domain with the co-existing $\alpha$ phase composition verifying that the phase precipitating from the matrix is the $\gamma_{2}$ phase.

\section{DISCUSSION}

Transformation behaviour of our $\mathrm{Cu}-\mathrm{Al}-\mathrm{Ni}$ alloy in stages 1 and 2 (see Fig. 2) is similar to that described

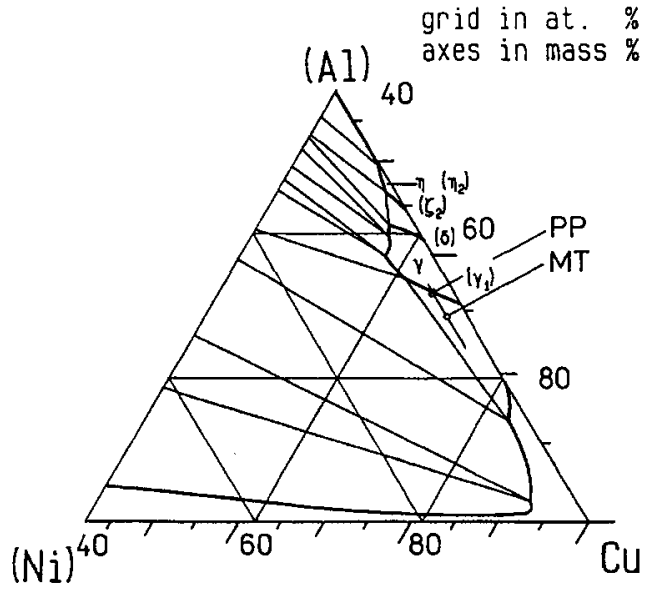

Figure 4. Cu-rich part of isothermal section at $500^{\circ} \mathrm{C}$ of the $\mathrm{Cu}-\mathrm{Al}-\mathrm{Ni}$ phase diagram based on results in [18]. Determined compositions of both $\gamma_{2}$ precipitates (PP) and matrix (MT) are shown. in the literature $[1,5,6,8,10]$. While it seems to be commonly accepted that an improvement in the short-range order may occur in stage 1 , the increase of the transformation temperatures in stage 2 has not been unequivocally explained yet. Van Humbeeck et al. [8] ascribed it to an improvement in the next-nearest-neighbour (nnn) order, while other authors [10] related it to $\gamma_{2}$ phase precipitation. Occurrence of $\gamma_{2}$ precipitates already at $\mathrm{T}_{\text {an }}=200^{\circ} \mathrm{C}$ was confirmed by TEM in our previous study on $\mathrm{Cu}-14.3 \mathrm{Al}-4.1 \mathrm{Ni}$ alloy $[5,6]$. As it is argued in paper [5], the stress and compositional changes in the vicinity of the $\gamma_{2}$ precipitates might facilitate the nucleation of martensite and, thus, enhance the $\mathrm{M}_{\mathrm{s}}$ temperature. The same mechanism can be, however, hardly accepted to explain the increase of $A_{s}$ and $A_{f}$ in stage 2. Only a part of this increase can be ascribed to a shift in the matrix composition due to the $\gamma_{2}$ phase precipitation [5]. Neither an improvement in the short-range atomic order, as proposed by Van Humbeeck et al. [8], is likely to be the dominant process during the whole stage 2: it is highly improbable that a process necessitating only a short-range ordering could coincide with the $\gamma_{2}$ phase precipitation, a process involving long-range diffusion.

In the present study, a continuous decrease of the resistivity of austenite $\left(R_{A}\right)$ has been detected during stages 1 and 2 (Fig. 2). Similar decrease of the resistivity was observed by Nakamura et al. [1] and by Van Humbeeck et al. [8], who attributed it to the nnn ordering. As mentioned above, this possibility is highly improbable in our case. Moreover, the finding of the $\gamma_{2}$ precipitates at $T_{a n}=200{ }^{\circ} \mathrm{C}[5]$ and at the same time the slight resistivity decrease at $\mathrm{T}_{\text {an }}<200^{\circ} \mathrm{C}$ (see Fig. 2) suggest that the extent of a shortrange ordering can be only slight in both stages 1 and 2 . Let us thus examine some other possible causes of the resistivity decrease.

The influence of the $\gamma_{2}$ precipitates on the resistivity will be discussed first. From the TEM micrographs taken in our previous work [5] we have estimated that the volume fraction of $\gamma_{2}$ precipitates in samples aged at $230^{\circ} \mathrm{C}$ was less than $4 \times 10^{-3}$. The resistivity decrease for $T_{\text {an }}=230^{\circ} \mathrm{C}$ was $\approx 6.2 \mathrm{n} \Omega \mathrm{m}$ (read at $20^{\circ} \mathrm{C}$, compared with the as-quenched state). The $\gamma_{2}$ precipitates may directly contribute to the resistivity decrease supposing that the resistivity of the $\gamma_{2}$ phase is less than that of the parent $\beta_{1}$ phase. However, limiting expressions for the resistivity of two-phase solids [15] show that even if the resistivity of the $\gamma_{2}$ phase were one fifth of that of the $\beta_{1}$ phase, the resistivity of the composite could not fall by more than $1.5 \mathrm{n} \Omega \mathrm{m}$ owing to the low volume fraction of the $\gamma_{2}$ phase $\left(<4 \times 10^{-3}\right)$. Moreover, the resistivity substantially increases at the beginning of stage 3 where the $\gamma_{2}$ precipitation is pronounced. Hence, we rather expect the $\gamma_{2}$ precipitates directly increase the resistivity, this effect being negligible at lower $T_{\text {an }}$ and manifesting itself in stages 3 and 4 .

Another reason of the resistivity decrease in stage 2 could be a change of the $\beta_{1}$-matrix composition during ageing. Due to the $\gamma_{2}$ precipitation the matrix becomes impoverished of $\mathrm{Al}$ (and possibly also 
$\mathrm{Ni}$ ) atoms. Supposing that the $\gamma_{2}$ phase is the stoichiometric $\mathrm{Cu}_{9} \mathrm{Al}_{4}$, the precipitates of the volume fraction of $4 \times 10^{-3}$ would deplete the matrix by $\approx 0.01$ at. $\% \mathrm{Al}$. The corresponding resistivity decrease can be roughly estimated as follows. The nominal composition of our alloy was $\mathrm{Cu}_{68.2}-\mathrm{Al}_{28.1}-\mathrm{Ni}_{3.7}$ and its resistivity in the as-quenched state was $\approx 92 \mathrm{n} \Omega \mathrm{m}$ (at $20^{\circ} \mathrm{C}$ ). We assume that in the $\mathrm{Cu}_{96.3-\mathrm{x}}-\mathrm{Al}_{\mathrm{x}}-\mathrm{Ni}_{3.7}$ system the resistivity reaches its relative minimum at $\mathrm{x}=25$ and sharply increases with increasing $\mathrm{Al}$ content, resembling e.g. the ordered $\mathrm{Cu}-\mathrm{Au}$ system. Though we do not know the resistivity of $\mathrm{Cu}_{71.3}-\mathrm{Al}_{25.0}-\mathrm{Ni}_{3.7}$, it will be certainly higher than that of pure $\mathrm{Cu}$, i.e. $>17 \mathrm{n} \Omega \mathrm{m}$ [15]. Thus, the resistivity difference between $\mathrm{Cu}_{68.2}-\mathrm{Al}_{28.1}-\mathrm{Ni}_{3.7}$ and $\mathrm{Cu}_{71.3}-\mathrm{Al}_{25.0}-\mathrm{Ni}_{3.7}$ is less than $92-17 \mathrm{n} \Omega \mathrm{m}=75 \mathrm{n} \Omega \mathrm{m}$ and the corresponding average resistivity slope is less than $75 /(28.1-25.0) \mathrm{n} \Omega \mathrm{m} / \mathrm{at} . \% \mathrm{Al}<25 \mathrm{n} \Omega \mathrm{m} / \mathrm{at} . \% \mathrm{Al}$. Then the matrix depletion by 0.01 at.\% Al results in a resistivity decrease less than $0.25 \mathrm{n} \Omega \mathrm{m}$. The effect of the possible matrix impoverishment of $\mathrm{Ni}$ can be estimated analogously. As the resistivity of $\mathrm{Cu}_{71.9}-\mathrm{Al}_{28.1}-\mathrm{Ni}_{0}$ is certainly higher than $17 \mathrm{n} \Omega \mathrm{m}$, the resistivity difference between $\mathrm{Cu}_{68.2}-\mathrm{Al}_{28.1}-\mathrm{Ni}_{3.7}$ and $\mathrm{Cu}_{71.9}-\mathrm{Al}_{28.1}-\mathrm{Ni}_{0}$ is less than $75 \mathrm{n} \Omega \mathrm{m}$ and the corresponding average resistivity slope is less than $75 / 3.7 \mathrm{n} \Omega \mathrm{m} / \mathrm{at} . \% \mathrm{Ni} \approx$ $20 \mathrm{n} \Omega \mathrm{m} /$ at.\% Ni. As the limit of solubility of $\mathrm{Ni}$ in the $\gamma_{2}$ phase is $\approx 8.5$ at.\% [18,19], the precipitates of the volume fraction of $4 \times 10^{-3}$ might deplete the matrix at most by $\approx 2 \times 10^{-2}$ at.\% Ni, which would bring about a resistivity decrease less than $20 \times 2 \times 10^{-2} \mathrm{n} \Omega \mathrm{m}=0.4 \mathrm{n} \Omega \mathrm{m}$. The local elemental analysis showed only slight difference in $\mathrm{Ni}$ content between the precipitates and the matrix, so $\mathrm{Ni}$ is out of suspicion of causing the resistivity decrease of $6.2 \mathrm{n} \Omega \mathrm{m}$.

It seems that the resistivity decrease in stage 2 can hardly be ascribed to the $\gamma_{2}$ precipitation. Searching for another explanation, the role of the quenched-in vacancies will be discussed next. Annealing out of the excess quenched-in vacancies as a cause of the shift of the transformation temperatures during ageing was suggested in [8] and adopted in our previous study [6].

In pure metals, the resistivity increase caused by vacancies is comparable to that caused by solute metal atoms. If this holds also in the case of our alloy, the resistivity decrease in stage 2 may be explained by annealing-out of (at least) 0.5 at.\% of vacancies. This explanation seems plausible for the following reasons. (a) The equilibrium concentration of thermal vacancies is generally high in intermetallic compounds with b.c.c.-derivative structures [16]. For instance, the vacancy concentration in a $\mathrm{Fe}_{3} \mathrm{Al}$ alloy with the $\mathrm{DO}_{3}$ structure was found to be $6.6 \times 10^{-2}$ at the melting temperature [17]. Similar values are reached in the $\mathrm{B} 2$ intermetallic compounds $[16,17]$; in some of them high vacancy supersaturation were found after quenching from high temperatures [16]. (b) In a $\mathrm{Cu}-\mathrm{Al}-\mathrm{Ni}$ shape memory alloy, ageing at a temperature between 200 and $275^{\circ} \mathrm{C}$ for 5 hours brought about a decrease in the mean positron annihilation lifetime, which grew with the ageing temperature [20]. If this decrease does not relate to an ordering (or precipitation) process, it is probably due to annealing-out of quenched-in vacancies. Then this result accords well with ours even in respect of the temperature region where the vacancies are annealed out during an isochronal annealing. (c) Furthermore, annealing-out of quenched-in vacancies may result in a resistivity decrease up to $\approx 15 \%$ in Au-Cd alloy with the $\mathrm{B} 2$ structure [21], i.e. a resistivity decrease similar to that observed in our stage 2 .

The process causing the resistivity decrease in stage 2 is probably responsible also for the increase of the transformation temperatures in this stage. The effect of vacancies on the transformation temperatures is not clear yet, but Murakami et al. [21] described a decrease in the transformation hysteresis by more than $20^{\circ} \mathrm{C}$ that was caused by annealing-out of quenched-in vacancies. Thus, we believe that the quenched-in vacancies probably play the dominant role in stage 2 .

Now we will briefly mention some phenomena observed in stages 3 and 4 .

As to stage 3, Nakamura et al. [1] observed a resistivity increase, an increase in the value of $A_{\mathbf{f}}-M_{s}$ and smooth transformation curves, but they did not describe any increase in the transformation temperatures similar to ours (see Fig. 2), probably because of not extending the ageing experiment to sufficiently high temperatures. We are not aware of a literature report on such an increase. Some authors who used samples of other shape and size $[5,10]$ observed an increase in the $A_{s}, A_{f}$ temperatures which was not accompanied by a comparable increase in the $M_{s}, M_{f}$ temperatures. On the other hand, similar steep increase in the transformation temperatures in stage 3 was found on $\mathrm{Cu}-14.3 \mathrm{Al}-4.1 \mathrm{Ni}$ also by calorimetric measurements [6]. As described in paper [6] this sharp increase is accompanied by a sudden 
change of the transformation mode. While in the stages 1 and 2 the austenite transforms into $\gamma_{1}$ ' martensite, transformation into a martensite with morphologically and crystallographically different structures occurs in stage 3 .

The sharp drop of $\Delta R$ in stage 4 apparently corresponds to decreased transformable volume of the specimen. This accords well with the $\mathrm{M}_{\mathrm{s}}$ fall in stage 4 (more undercooling is necessary for the matrix to transform). The underlying process is probably the $\alpha$ phase precipitation; it was detected in specimens severely overaged at $400^{\circ} \mathrm{C}$ [4].

\section{CONCLUSIONS}

Ageing of $\mathrm{Cu}-14.3 \overrightarrow{\mathrm{A}} \mathrm{l}-4.1 \mathrm{Ni}$ (wt.\%) shape memory alloy has been investigated. Using resistivity measurements principally, the following results were obtained.

(1) On the basis of the resistivity and $M_{s}, A_{f}$ changes, four stages can be distinguished in isochronal annealing at temperatures up to $400^{\circ} \mathrm{C}$. The resistivity of austenite decreases in stages 1,2 and increases in stages 3,4 . A slight decrease in $M_{s}, A_{f}$ is observed in stage 1 , while in stages 2 and $3 M_{s}, A_{f}$ increase. The $M_{s}, A_{f}$ increase in stage 3 is much greater than that in stage 2. In stage $4, M_{s}$ decreases again and the alloy ability of the martensitic transformation is being lost.

(2) The $M_{s}, A_{f}$ and resistivity shifts in stage 2 are probably caused by annealing-out of the excess quenched-in vacancies.

\section{Acknowledgement}

This study was supported by the Grant Agency of the Academy of Sciences of the Czech Republic under Contracts No. A1010909 and No. A1010817.

\section{References}

1. Nakamura F., Kusui J., Shimizu Y., Takamura J., J. Japan Inst. Metals 44, 1302 (1980).

2. Singh J., Chen H., Wayman C.M., Metall. Trans. A 17A, 65 (1986).

3. Kuwano N., Wayman C.M., Metall. Trans. A 15A, 621 (1984).

4. Kennon N.F., Dunne D.P., Middleton L., Metall. Trans. A 13A, 55 (1982) 1.

5. Zárubová N., Gemperle A., Novák V., Mater. Sci. Eng. A 222, 166 (1997).

6. Zárubová N., Gemperle A., Novák V., Journal de Physique, Colloque C5 , 7, 281 (1997).

7. Singh J., Chen H., Wayman C.M., Scr. Metall. 19, 887 (1985).

8. Van Humbeeck J., Chandrasekaran M., Delaey L., ISIJ Int., 29, 388 (1989).

9. Sakamoto H., Shimizu K., ISIJ Int. 29, 395 (1989).

10. Rodríguez P., Guénin G., Mater. Sci. Eng. A129, 273 (1990).

11. Sakamoto H., Sugimoto K., Nakamura Y., Tanaka A., Shimizu K., Mater. Trans. JIM 32, 128 (1991).

12. Tadaki T., Shimizu K., Trans. Mat. Res. Soc. Jpn. 18B, 897 (1994).

13. Picornell C., Pons J., Cesari E., Journal de Physique, Colloque C5 , 7, 323 (1997).

14. Christian J.W.: The Theory of Transformations in Metals and Alloys, Pergamon Press, Oxford 1975.

15. Rossiter P. L.: The electrical resistivity of metals and alloys, Cambridge University Press 1987.

16. Yamaguchi M., Shirai Y., in Stoloff N. S., Sikka V. K. (eds.): Physical Metallurgy and Processing of Intermetallic Compounds, Chapman \& Hall, 1998.

17. Schaefer H.-E., Würschum R., Bub J., Mater. Sci. Forum 105-110, 439 (1992).

18. Koester W., Zwicker U., Moeller K., Z. Metallkde 39, 225 (1948).

19. Bradley A. J., Lipson H., Proc. Roy. Soc. 167A, 42 (1938) 1.

20. Hurtado I., Segers D., Dorikens-Vanpraet L., Dauwe C., Van Humbeeck J., J. Phys. IV, Suppl. J. Phys. III 5, C8-949 (1995).

21. Murakami Y., Nakajima Y., Otsuka K., Scr. Mater. 34, 955 (1996). 